\title{
The Relevance of a Study of a Temperature-sensitive Ballooning Mutant of Aspergillus nidulans Defective in Mannose Metabolism to our Understanding of Mannose as a Wall Component and Carbon/Energy Source
}

\author{
By B. P. VALENTINE* AND B. W. BAINBRIDGE \\ Department of Microbiology, Queen Elizabeth College, \\ Campden Hill, London W8 $7 \mathrm{AH}$
}

(Received 4 July 1978)

\begin{abstract}
A temperature-sensitive mutant strain of Aspergillus nidulans has been isolated which failed to grow normally on minimal agar medium at $43{ }^{\circ} \mathrm{C}$ unless mannose was supplied as a sole carbon source. The mutant has been given the symbol $m n r A 455$ for mannose relief. Under restrictive conditions $\left(43^{\circ} \mathrm{C}\right)$ the mutant produced extensive areas of swollen hyphae, called balloons, and wall preparations from cultures grown at $40{ }^{\circ} \mathrm{C}$ had approximately one-third of the mannose found in walls of control cultures. The mnrA455 strain produced a more thermolabile phosphomannose mutase than the wild-type strain, so it is suggested that the mutation is in the structural gene coding for this enzyme.

The mnrA455 strain failed to grow on minimal agar medium containing $0 \cdot 1 \%(\mathrm{w} / \mathrm{v})$ mannose and $0.9 \%(\mathrm{w} / \mathrm{v})$ glucose at $43{ }^{\circ} \mathrm{C}$. This property was used to obtain revertants, one of which was a double mutant mnrA455 manAl. Growth of the double mutant in media containing $\left[{ }^{14} \mathrm{C}\right]$ mannose at $43{ }^{\circ} \mathrm{C}$ showed that $84 \%$ of the label found in the wall occurred in mannose in comparison with $33 \%$ in the wild-type control. Autoradiography of cultures of the double mutant using $\left[{ }^{3} \mathrm{H}\right]$ mannose showed predominant incorporation of label into the tip region of growing hyphae. A manAl strain, isolated following haploidization of a diploid, was unable to grow on media containing glucose or mannose alone. The manAI strain had reduced phosphomannose isomerase (EC 5.3.1.8) activity. The manAl mutation, which is epistatic to $m n r A 455$, has been located to linkage group VIII and the $m n r A 455$ mutation to linkage group V. A pathway is presented for the utilization of mannose in $A$. nidulans.
\end{abstract}

\section{INTRODUCTION}

Although temperature-sensitive mutants have proved to be a powerful tool for the analysis of essential functions in a wide range of micro-organisms, such mutants have not been exploited in the analysis of cell wall synthesis in Aspergillus nidulans, apart from a study by Rosenberger and co-workers (Cohen et al., 1969) who isolated a temperaturesensitive mutant which had reduced glucosamine in the wall and had lost mechanical strength (Katz \& Rosenberger, 1970). The present investigation reports the isolation and analysis of a temperature-sensitive growth mutant which is specifically relieved by mannose, a phenotype not previously reported in filamentous fungi. This property has been used to analyse the utilization of mannose for wall synthesis and as a sole source of carbon and energy.

* Present address : Beecham Pharmaceuticals, Clarendon Road, Worthing, Sussex BN14 8QH. 


\title{
Table 1. Genotypes of strains used in chromosome mapping and biochemical analyses of mnrA455 and manA1 mutations
}

Strain no.*
BWB140
BWB152
G95 (M.S.F.)
G53
G83
BV95
BV455
BV601
BV602
BV603

\author{
Genotype
}

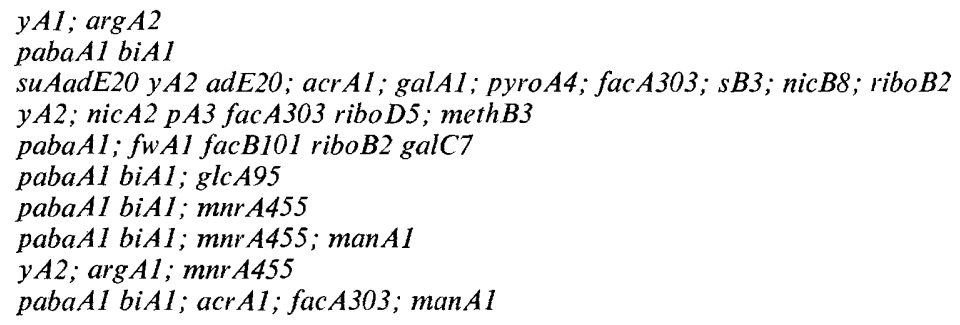

* BWB and BV strains are held at Queen Elizabeth College; G strains were obtained from the Institute of Genetics, University of Glasgow. Origins of strains and details of gene symbols can be found in Clutterbuck (1974).

\section{METHODS}

Organisms. The parental strain, $A$, nidulans BWB152 (pabaAl biAl), required $p$-aminobenzoic acid and biotin for growth. It was treated with $N$-methyl- $N^{\prime}$-nitro- $N$-nitrosoguanidine (NTG) (Clutterbuck \& Sinha, 1966) to yield a mutant $m n r A 455$ (BV455) which failed to grow on minimal agar medium plus $1 \%(\mathrm{w} / \mathrm{v})$ glucose at $43{ }^{\circ} \mathrm{C}$ but which could grow at this temperature on minimal medium plus $1 \%(\mathrm{w} / \mathrm{v})$ mannose. The double mutant mnrA455 manAl (Bv601) was isolated as described in Results. Other strains were obtained from stocks held at Queen Elizabeth College or at the University of Glasgow (Table 1).

Media. Minimal medium (MM) and complete medium (CM) were essentially those of Pontecorvo et al. (1953) with the addition to both of $\mathrm{CuSO}_{4} \cdot 5 \mathrm{H}_{2} \mathrm{O}$ at $5 \mu \mathrm{g} \mathrm{ml}^{-1}$ and the modification of $\mathrm{CM}$ as suggested by MacIntosh \& Pritchard (1963). Sodium deoxycholate $(0.01 \%, \mathrm{w} / \mathrm{v})$ was added to media to reduce colony diameter if necessary (MacIntosh \& Pritchard, 1963), and supplements were added to MM as required. Carbon sources were sterilized separately by filtration or autoclaving at $109^{\circ} \mathrm{C}$ for $10 \mathrm{~min}$ and added at a concentration of $1 \%(\mathrm{w} / \mathrm{v})$ unless otherwise stated. To solidify media, $1.5 \%(\mathrm{w} / \mathrm{v})$ agar (Davis) was added.

Cultural conditions. Cultures were incubated at $30^{\circ} \mathrm{C}$ (permissive temperature) or at $43^{\circ} \mathrm{C}$ (restrictive temperature) unless otherwise stated. The $43^{\circ} \mathrm{C}$ incubator was of the fan-assisted type to reduce the time taken to reach $43^{\circ} \mathrm{C}$ after sampling. Cultures for wall isolation were grown for $48 \mathrm{~h}$ at a semi-restrictive temperature of $40^{\circ} \mathrm{C}$ in 41 liquid $\mathrm{MM}$ in a 6 I conical flask. Conidia were inoculated to give a final concentration of $10^{5} \mathrm{ml}^{-1}$. The flask was magnetically stirred and aerated vigorously with compressed air using a sintered-glass sparger. To obtain mycelium for enzyme extracts, $500 \mathrm{ml} \mathrm{MM}$ in 11 conical flasks were inoculated, stirred and sparged as before and harvested in the mid-exponential phase of growth. Glucose and/or mannose were added at the concentrations indicated in Results.

Fluorescence microscopy. Intact hyphae were stained for $\beta$-linked carbohydrates (Maeda \& Ishida, 1967) by suspending them in a $0.5 \%(\mathrm{w} / \mathrm{v})$ solution of Photine HV (kindly supplied by Hickson \& Welch, Castleford, Yorks) in $0.025 \mathrm{M}$-sodium cacodylate buffer $\mathrm{pH} 7 \cdot 2$. Purified wall preparations were checked for protein contamination by staining in $0.1 \mathrm{mM}-\mathrm{N}$-tolyl-1-naphthylamine-8-sulphonic acid in $1 \mathrm{M}-\mathrm{NaCl}$ (Newton, 1954). Both preparations were viewed under a Nikon Apophot photomicroscope in the fluorescence mode using the following filters: exciter 4, mirror 1 and barrier 1 .

Fixation. Except for fluorescence work, all hyphae were fixed in $4 \%(\mathrm{v} / \mathrm{v})$ glutaraldehyde in $0.025 \mathrm{M}^{-}$ sodium cacodylate buffer pH 7.2.

Photomicroscopy. A Nikon Apophot photomicroscope was used for bright field and fluorescence photography. Films used were Micro Neg PanB (llford), Agfacolor (Agfa-Gevaert) and HP4 (llford).

Radial growth rate determination. Samples of conidial suspension (about $20 \mu 1 ; 10^{6}$ spores $\mathrm{ml}^{-1}$ ) were inoculated on to MM agar at three places with a finely drawn Pasteur pipette. When linear growth was achieved, colony diameters were measured at intervals using a Baty projector (J. E. Baty \& Co., Burgess Hill, Sussex). For each colony, measurements were taken at right angles and mean radial growth rates were calculated from at least three colonies.

Genetic techniques. These were essentially those of Pontecorvo et al. (1953) with the exception of the arginine crossing technique (Bainbridge, 1974) and the use of $p$-fluorophenylalanine $(0.005$ to $0.02 \%$, w/v) for haploidization of diploids (Lhoas, 1961).

Purification of walls. The method used was based on that of Mahadevan \& Tatum (1965). Most operations 
were carried out at $4{ }^{\circ} \mathrm{C}$ and all operations, except drying, were done at below $10^{\circ} \mathrm{C}$ to minimize enzymic degradation (Taylor \& Cameron, 1973). Mycelium was grown as described above, collected by filtration, washed with distilled water and passed twice through a French pressure cell (American Instrument Co., Silver Spring, Md, U.S.A.) at $1 \cdot 2 \times 10^{8} \mathrm{~Pa}$. The disrupted material was centrifuged at $10000 \mathrm{~g}$ for 2 min and the pellet was collected. Similar centrifugations were carried out to collect the walls at each of the following operations. The pellet was washed three times with distilled water and suspended in $200 \mathrm{ml} 1 \%(\mathrm{w} / \mathrm{v})$ sodium dodecyl sulphate. This suspension was magnetically stirred for $16 \mathrm{~h}$ at $4{ }^{\circ} \mathrm{C}$, centrifuged as before, and the pellet was washed three times with distilled water and passed twice through the French pressure cell. The wall preparation was then washed approximately eight times with distilled water, ultrasonically disrupted for $2 \mathrm{~min}$ (MSE $100 \mathrm{~W}$ ultrasonicator), washed with $0.05 \mathrm{M}$-phosphate buffer $\mathrm{pH} 7$, washed a further eight times with distilled water and ultrasonically disrupted for a further $2 \mathrm{~min}$. The preparation was then examined for protein contamination by fluorescence microscopy as described above. If no contamination was visible, the preparation was washed with increasing concentrations of ethanol and dried from absolute ethanol at $37^{\circ} \mathrm{C}$. The sample was then ground using a pestle and mortar, weighed and stored at $4{ }^{\circ} \mathrm{C}$ in a desiccator over silica gel.

Estimation of neutral sugars. Wall preparation $(20 \mathrm{mg})$ was hydrolysed for $6 \mathrm{~h}$ in $1 \mathrm{ml} 1 \mathrm{M}^{-\mathrm{H}_{2}} \mathrm{SO}_{4}$ at $104{ }^{\circ} \mathrm{C}$ in a sealed glass ampoule. The hydrolysate was neutralized with $\mathrm{BaCO}_{3}$, centrifuged at $10000 \mathrm{~g}$ for 2 min and the supernatant was analysed by a method based on that of Wilson (1959). A sample (10 to $80 \mu 1)$ of the supernatant was spotted on to Whatman no. 1 paper and subjected to descending chromatography for $30 \mathrm{~h}$ with ethyl acetate/pyridine/water $(8: 2: 1$, by vol.) as solvent. The paper was dried, dipped in aniline phthalate reagent (Wilson, 1959), redried and heated at $104{ }^{\circ} \mathrm{C}$ for $11 \mathrm{~min}$. The spots were then cut out and eluted in $80 \%(\mathrm{v} / \mathrm{v})$ ethanol for $2 \mathrm{~h}$ with occasional shaking. The absorbance at $390 \mathrm{~nm}$ was estimated in a SP600 spectrophotometer (Pye Unicam).

Estimation of amino sugars. Wall preparation $(20 \mathrm{mg})$ was hydrolysed for $6 \mathrm{~h}$ at $104{ }^{\circ} \mathrm{C}$ in $1 \mathrm{ml} 6 \mathrm{M}-\mathrm{HCl}$ in a sealed glass ampoule. The hydrolysate was centrifuged and the supernatant was dried under vacuum over $\mathrm{NaOH}$. The residue was suspended in $1 \mathrm{ml}$ distilled water and stored at $-10^{\circ} \mathrm{C}$. The resuspended hydrolysate was treated by the method of Stoffyn \& Jeanloz (1954) to reduce hexosamines quantitatively to pentoses: $20 \mu \mathrm{l}$ hydrolysate was mixed with $20 \mu \mathrm{l} 2 \%(\mathrm{w} / \mathrm{v})$ ninhydrin solution containing $4 \%(\mathrm{v} / \mathrm{v})$ pyridine and heated at $104^{\circ} \mathrm{C}$ for $20 \mathrm{~min}$ in a sealed glass capillary tube. The pentoses produced were separated chromatographically and assayed by the methods described above for neutral sugars except that absorbance was read at $360 \mathrm{~nm}$. The techniques for neutral and amino sugars were tested by subjecting a mixture of sugars, based on the known composition of $A$. nidulans walls (Bull, 1970), to the same procedures.

Estimation of lipids. Bound lipids were estimated by the method of Johnston (1965). Wall preparation $(0.5 \mathrm{~g})$ was refluxed for $1 \mathrm{~h}$ at $50{ }^{\circ} \mathrm{C}$ with $100 \mathrm{ml}$ of diethyl ether/absolute ethanol $/ 6 \mathrm{M}-\mathrm{HCl}(50: 50: 1$, by vol.). The remaining wall was centrifuged at $10000 \mathrm{~g}$ for $10 \mathrm{~min}$, washed several times in ethanol and dried as above. The supernatant was also dried and weighed.

Autoradiography. The method described by Katz \& Rosenberger (1971) was used with the following modifications. Conidia were inoculated (final concentration $10^{6} \mathrm{ml}^{-1}$ ) into $25 \mathrm{ml} \mathrm{MM}$ plus $0.09 \%(\mathrm{w} / \mathrm{v}$ ) glucose and $0.01 \%(\mathrm{w} / \mathrm{v})$ mannose, both filter sterilized, in a $100 \mathrm{ml}$ flask. The culture was stirred and aerated as described above for $16 \mathrm{~h}$ at $43^{\circ} \mathrm{C}$. The hyphae were centrifuged and resuspended in $2 \mathrm{ml}$ of the same medium at $43{ }^{\circ} \mathrm{C}$ in a boiling tube, aerated as before and incubated in a water-bath at $43^{\circ} \mathrm{C}$ for $1 \mathrm{~h}$. $\left[2{ }^{3} \mathrm{H}\right]$ Mannose $\left(100 \mu \mathrm{Ci} ; 1.0 \mathrm{Ci} \mathrm{mmol}^{-1}\right.$; The Radiochemical Centre, Amersham) was then added, and $0.02 \mathrm{ml}$ samples of hyphal suspension were taken at intervals and immediately extracted for 20 min with $2 \mathrm{ml}$ distilled water at $100{ }^{\circ} \mathrm{C}$. This was followed by extraction for $20 \mathrm{~min}$ with $70 \%$ ethanol at $50{ }^{\circ} \mathrm{C}$, for $1 \mathrm{~min}$ with $1 \mathrm{M}-\mathrm{NaCl}$ and for $1 \mathrm{~min}$ with $0.2 \%(\mathrm{w} / \mathrm{v})$ sodium dodecyl sulphate, with distilled water washes between each extraction. Hyphae were then extracted for $1 \mathrm{~min}$ with absolute ethanol, for $30 \mathrm{~min}$ with chloroform/methanol $(2: 1, \mathrm{v} / \mathrm{v})$, followed by extraction with decreasing concentrations of ethanol in water and finally distilled water. All operations were done at room temperature, unless otherwise stated, and at the start of each of the above extractions the hyphae were ultrasonically disrupted for $10 \mathrm{~s}$. The hyphae were dried on to cleaned gelatin-coated slides, covered with AR10 stripping film (Kodak), dried again and left for 1 week at $4{ }^{\circ} \mathrm{C}$ in the dark. The slides were developed with D10 developer and fixed with Hypam fixer containing hardener (IIford). Hyphae were photographed as described above.

Cell-free extracts. Mycelium was grown as indicated above, collected by filtration, washed with $100 \mathrm{ml}$ cold distilled water, and suspended in $10 \mathrm{ml}$ extraction buffer $(0.05 \mathrm{M}$-triethanolamine buffer $\mathrm{pH} 7.6 \mathrm{con}-$ taining $0.05 \mathrm{M}-\mathrm{MgCl}_{2}$ ). This suspension was centrifuged and the mycelial pellet was resuspended in $7.5 \mathrm{ml}$ extraction buffer. The suspension was disrupted by passage four times through a French pressure cell, centrifuged at $100000 \mathrm{~g}$ in an MSE65 ultracentrifuge for $30 \mathrm{~min}$ and the supernatant was used immediately for enzyme assays. All the above operations were done at 0 to $4{ }^{\circ} \mathrm{C}$.

Enzyme assays. Enzymes catalysing the interconversion of glucose and mannose phosphate esters were assayed in a coupled system in which the final reaction was the conversion of glucose 6-phosphate to 
Table 2. Additions made to the basic reaction mixture* for assay of enzymes involved in the interconversion of glucose and mannose phosphate esters

\section{Enzyme assayed}

Glucose-6-phosphate dehydrogenase

[EC 1.1.1.49]

Phosphoglucose mutase

[EC 2.7.5.1]

Phosphoglucose isomerase

[EC 5.3.1.9]

Phosphomannose isomerase

[EC 5.3.1.8]

Phosphomannose mutase
Hexose monophosphate

Glucose 6-phosphate

Glucose 1-phosphate

Fructose 6-phosphate

Mannose 6-phosphate

Mannose 1-phosphate
Glucose 1,6bisphosphate $\dagger$

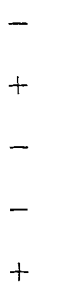

* See Methods. ++ , Present; - , absent.

6-phosphogluconate catalysed by NADP-linked glucose-6-phosphate dehydrogenase. NADP reduction was followed by the increase in absorbance at $340 \mathrm{~nm}$ using an SP1700 spectrophotometer (Pye-Unicam). Assay temperatures were as indicated in Results. Chemicals (from Sigma) were of the highest grade generally available. The basic reaction mixture, modified from a method of Boehringer Mannheim (1975) for the assay of glucose 6-phosphate, contained (in 1.2 ml): $0.05 \mathrm{M}$-triethanolamine buffer pH 7.6, 0.05 $\mathrm{M}-\mathrm{MgCl}_{2}, 0.3 \mu \mathrm{mol}$ NADP (Na salt), 2 units glucose-6-phosphate dehydrogenase, $1 \mu \mathrm{mol}$ of the appropriate hexose monophosphate, $0.03 \mu \mathrm{mol}$ glucose 1,6-bisphosphate (when required) and $0.1 \mathrm{ml}$ cell-free extract. Glucose $1,6-$ bisphosphate was required as a cofactor for the assay of phosphoglucose mutase and phosphomannose mutase as chemically prepared hexose monophosphates were used. Table 2 shows the additions made to the basic reaction mixture for the assay of particular enzymes. The enzyme activities were found to be ranked in the order phosphoglucose isomerase $>$ phosphomannose isomerase $>$ phosphomannose mutase and consequently it was unnecessary to add phosphoglucose isomerase when assaying phosphomannose isomerase or to add phosphoglucose isomerase and phosphomannose isomerase when assaying phosphomannose mutase. Addition of these enzymes caused no observable increase in activity of the enzyme being assayed. Protein was estimated by the method of Lowry et al. (1951) using bovine serum albumin as standard. Enzyme activities were expressed as units (mg protein $)^{-1}$ where one unit was defined as an activity producing

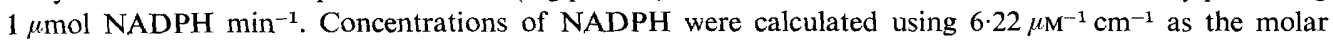
extinction coefficient (Horecker \& Kornberg, 1948).

Labelling of the wall with $\left[{ }^{14} \mathrm{C}\right]$ mannose. Conidia (final concentration $10^{5} \mathrm{ml}^{-1}$ ) were inoculated into $25 \mathrm{ml}$ liquid MM containing $0.95 \%(\mathrm{w} / \mathrm{v})$ glucose, $0.05 \%(\mathrm{w} / \mathrm{v})$ mannose and $\left[\mathrm{U}-{ }^{14} \mathrm{C}\right] \mathrm{mannose}\left(0.01 \mu \mathrm{Ci} \mathrm{ml^{-1 }}\right.$; $5 \mathrm{mCi} \mathrm{mol}^{-1}$; The Radiochemical Centre, Amersham). The medium was incubated in $250 \mathrm{ml}$ flasks on a rotary shaker (Gallenkamp) at $200 \mathrm{rev} . \mathrm{min}^{-1}$ for $48 \mathrm{~h}$ at 30 or $43{ }^{\circ} \mathrm{C}$. Walls were purified and sugars were separated as described above. Spots were cut out from chromatograms and oxidized in a Packard Tricarb sample oxidizer which trapped the ${ }^{14} \mathrm{CO}_{2}$ formed in a scintillation mixture containing $5 \mathrm{ml}$ methanol, $3 \mathrm{ml}$

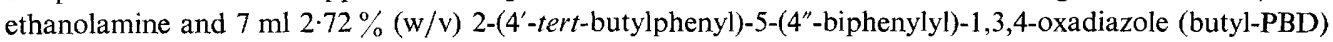
in toluene. Radioactivity was determined in a Beckman model LS233 liquid scintillation counter.

\section{RESULTS}

\section{Growth responses of $\mathrm{BV} 455$ and isolation of the double mutant $\mathrm{BV} 601$}

Strain Bv455 (mnr A455) grew very slowly on MM agar plus $1 \%(\mathrm{w} / \mathrm{v})$ glucose at $43{ }^{\circ} \mathrm{C}$ (Table 3) and hyphae with swollen regions, called balloons, were formed which stained intensely with the fluorescent stain Photine HV (Fig. 1). The strain grew normally if glucose was replaced by $1 \%(\mathrm{w} / \mathrm{v})$ mannose (Table 3$)$, but failed to grow if both glucose $(0.9 \%)$ and mannose $(0 \cdot 1 \%)$ were present. The parental strain, BVB 152 , grew on all three media. The ratio of the two sugar concentrations was the important factor as inhibition of $\mathrm{Bv} 455$ also occurred on $0.09 \%$ glucose $10.01 \%$ mannose. One explanation of this inhibition by glucose was that there might be competition between mannose and glucose for a common permease system so that only a reduced amount of mannose entered the cell. Part of this mannose might be used as a carbon and energy source, leaving insufficient to relieve the mannose requirement. If this explanation is correct, then isolation of revertants of BV 455 on MM plus 

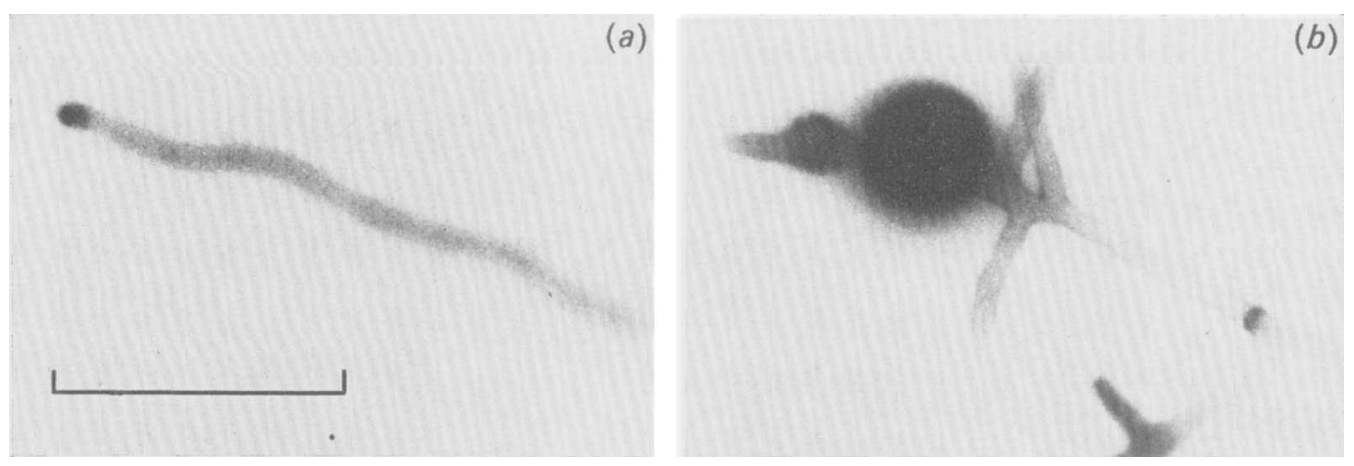

Fig. 1. Photomicrographs of hyphae of $A$. nidulans stained with a $0.5 \%(\mathrm{w} / \mathrm{v})$ aqueous solution of Photine HV. Preparations were photographed under a Nikon Apophot microscope with fluorescence attachment (negative prints from fluorescent transparencies). (a) BWB152 (mnr $A^{+}$) growing at $43^{\circ} \mathrm{C}$; (b) BV455 (mnr A455) growing at $43^{\circ} \mathrm{C}$; note the balloons. Bar marker represents $40 \mu \mathrm{m}$.

Table 3. Growth responses at $43{ }^{\circ} \mathrm{C}$ of parental and mutant strains on $M M$ supplemented with different carbon sources

\begin{tabular}{llccc} 
& & \multicolumn{2}{c}{ Growth response on MM containing: } \\
Strain & \multicolumn{1}{c}{ Genotype } & $1 \%$ Glucose & $\mathbf{1 \%}$ Mannose & $0.9 \%$ Glucose/ \\
BWB152 & pabaAl biAl & + & + & + \\
BV455 & pabaAl biAl; mnrA455 & - & + & - \\
Bv601 & $\begin{array}{l}\text { pabaAl biAl; mnrA455; } \\
\text { manAl }\end{array}$ & - & - & +
\end{tabular}

+ , Growth; - , slow or no growth.

Growth of BWB152 and Bv455 at $30{ }^{\circ} \mathrm{C}$ was normal but Bv601 grew less well on MM plus $1 \%$ glucose and failed to grow on $1 \%$ mannose or $0.9 \%$ mannose $/ 0.1 \%$ glucose (see Fig. $2 b$ ).

glucose and mannose might yield a mutant affected in mannose catabolism so that there would be sufficient mannose for the relief of the wall lesion. To test this, conidia $\left(10^{7} \mathrm{ml}^{-1}\right)$ were treated with NTG for $10 \mathrm{~min}$ and plated on MM plus $0.9 \%$ glucose and $0.1 \%$ mannose at a density of $10^{5}$ to $10^{7}$ per plate. These were incubated at $43{ }^{\circ} \mathrm{C}$ for $4 \mathrm{~d}$ and 50 revertants were isolated and purified by single colony isolation. Analysis of these strains on MM plus glucose and MM plus mannose showed that 49 were true revertants with a wild-type phenotype and one (strain Bv601) was the predicted double mutant, later given the genotype mnrA455 manA1 (Table 3). The double mutant could not grow on glucose or mannose MM presumably because glucose could not be used for wall synthesis and mannose could not be used as a carbon and energy source. Estimates of radial growth rates of the three strains were made at $43{ }^{\circ} \mathrm{C}$ on $\mathrm{MM}$ containing different ratios of glucose to mannose but a constant $1 \%$ of total sugar (Fig. $2 a$ ). The parental strain was little affected and the basic response of the mutant strains was confirmed. Replacement of mannose by glucose led to a progressive reduction in the growth rate of BV455 as the glucose concentration increased. Growth was poor except at concentrations of $0.975 \%$ and $1 \%$ mannose. The double mutant had an optimum growth rate on $0.9 \%$ glucose $10.1 \%$ mannose and failed to grow on glucose alone or in the presence of $0.5 \%$ mannose or above. When this experiment was repeated at $30^{\circ} \mathrm{C}$, strain BV455 grew normally whereas Bv601 showed a partially mutant phenotype (Fig. $2 b$ ). This means that the manAl mutation is only partially temperature-sensitive. 


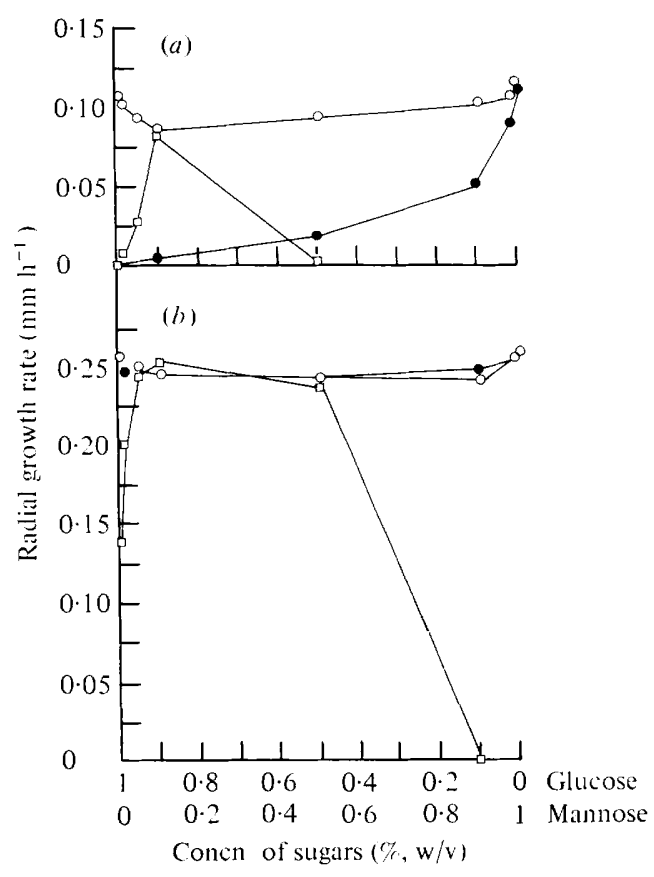

Fig. 2. Radial growth rate of $A$. nidulans strains growing on $\mathrm{MM}$ with different concentrations of mannose and glucose at $43{ }^{\circ} \mathrm{C}(a)$ or $30^{\circ} \mathrm{C}(b)$. , BWB152 (parental strain); , BV455 (mnr 4455$)$; [], BV601 (mnrA455 manAl).

Table 4. Classification of progeny from a cross between $\mathrm{Bv601}$ (pabaA1 biAl; mnrA455; manA1) and $\mathrm{BWB} 140(y A 1 ; \arg A 2)$

Growth response at $43^{\circ} \mathrm{C}$ on $\mathrm{MM}$ containing:

\begin{tabular}{|c|c|c|c|c|}
\hline Phenotype & $\begin{array}{l}\text { No. of } \\
\text { colonies }\end{array}$ & $1 \%$ Glucose & $1 \%$ Mannose & $\begin{array}{l}0.9 \% \text { Glucose } / \\
0.1 \% \text { Mannose }\end{array}$ \\
\hline$m n r A^{+} \operatorname{man} A^{+}$ & 48 & + & + & + \\
\hline$m n r A \operatorname{man} A^{+}$ & 43 & - & + & - \\
\hline $\left.\begin{array}{l}m n r A \operatorname{man} A \\
m n r A^{+} \operatorname{man} A\end{array}\right\}$ & 95 & - & - & + \\
\hline Total & 186 & & & \\
\hline & $2=0.35$ & \multicolumn{3}{|c|}{$P=0.85$ (fit to $1: 1: 2$ ratio) } \\
\hline
\end{tabular}

\section{Genetic analysis of $\mathrm{mnr} A 455$ and manAl}

A cross between BV455 (mnr $A 455$ ) and BwB140 (wild-type) gave $47 m n r A$ and $53 m n r A^{+}$ colonies, supporting the conclusion that $m n r A$ was a single gene mutation. Strain Bv601 ( $m$ m $A 455$ manAl) was also crossed with BWB140 and the progeny were tested on MM plus $1 \%$ glucose, $1 \%$ mannose or $0.9 \%$ glucose $/ 0.1 \%$ mannose. Only three phenotypes were detected and the double mutant $\operatorname{mnr} A$ man $A$ could not be distinguished from $m n r A^{+}$man $A$ under these conditions (Table 4). It was concluded that mnrA and man $A$ were located at unlinked loci and that man $A$ was epistatic to $m n r A$.

Two diploids were isolated between the master strain G95 and BV455 or Bv601 (Table 1). Approximately 150 haploids were isolated from each diploid and the markers present were classified. mnr $A 455$ segregated completely with $f a c A^{+}$while other linkage groups segregated independently, indicating that the $m n r A$ locus was on linkage group V. Similarly man $A 1$ segregated completely with $r i b o B^{+}$locating this locus to linkage group VIII. Strain BV603, 
Table 5. Recombination data from crosses involving manAl and mnrA455

\begin{tabular}{|c|c|c|c|c|c|}
\hline \multirow[b]{2}{*}{$\begin{array}{c}\text { Cross } \\
\text { no. }\end{array}$} & \multirow[b]{2}{*}{$\begin{array}{l}\text { Parental } \\
\text { strains }\end{array}$} & \multirow[b]{2}{*}{ Interval } & \multicolumn{2}{|c|}{ Progeny genotypes } & \multirow{2}{*}{$\begin{array}{c}\text { Frequency of } \\
\text { recombination } \\
(\%)\end{array}$} \\
\hline & & & Parental & Recombinant & \\
\hline 1 & BV $455 \times$ G 53 & $\begin{array}{l}\text { nic } A-m n r A 455 \\
m n r A 455-p A\end{array}$ & $\begin{array}{l}125 \\
161\end{array}$ & $\begin{array}{l}74 \\
38\end{array}$ & $\begin{array}{l}37 \cdot 2 \pm 4 \cdot 3 \\
19 \cdot 1 \pm 3 \cdot 1\end{array}$ \\
\hline 2 & BV $95 \times$ G 53 & $\begin{array}{l}\text { nic } A-g l c A 95 \\
\text { glc } A 95-p A\end{array}$ & $\begin{array}{r}98 \\
112\end{array}$ & $\begin{array}{l}46 \\
32\end{array}$ & $\begin{array}{l}32 \cdot 0 \pm 4 \cdot 7 \\
22 \cdot 2 \pm 3 \cdot 9\end{array}$ \\
\hline 3 & BV602× BV95 & glc A95-mnrA455 & 97 & 3 & $3 \cdot 0 \pm 1 \cdot 7$ \\
\hline 4 & $*_{\mathrm{BV}} 603 \times \mathrm{G} 83$ & $\operatorname{man} A 1-r i b o B 2$ & 118 & 1 & $0.85 \pm 0.85$ \\
\hline
\end{tabular}

Map of chromosome $\mathrm{V}$ markers based on crosses 1, 2 and 3

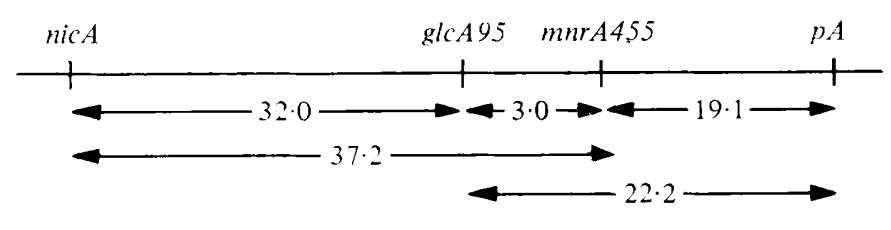

* Involves linkage group VIII only.

Table 6. Wall composition of strains BWB152 (parental) and BV455 (mnr A455) grown at $40^{\circ} \mathrm{C}$ in liquid $\mathrm{MM}$ plus $1 \%$ glucose for $48 \mathrm{~h}$

$\begin{array}{lccc}\text { Component } & & & \text { BV455 } \\ \text { Glucose } & 39 \cdot 0 & \text { BV455* } & \text { BWB152 } \\ \text { Glucosamine } & 13 \cdot 5 & 41 \cdot 0 & 105 \cdot 1 \\ \text { Galactose } & 9 \cdot 5 & 20 \cdot 3 & 150 \cdot 4 \\ \text { Mannose } & 4 \cdot 0 & 9 \cdot 5 & 100 \cdot 0 \\ \text { Galactosamine } & 2 \cdot 3 & 1 \cdot 5 & 37 \cdot 5 \\ \text { Lipid } & 10 \cdot 2 & 1 \cdot 4 & 60 \cdot 9 \\ \text { Protein } & 3 \cdot 5 & 7 \cdot 7 & 75 \cdot 5 \\ \quad \text { Total } & 82 \cdot 0 & 3.9 & 111 \cdot 4 \\ & & 85 \cdot 3 & \end{array}$

carrying manA1 but not $m n r A 455$, was isolated from the diploid G95/Bv601 by selecting for $m a n A$ and $f a c A$, selection for the latter marker automatically selecting for $m n r A^{+}$. Meiotic analysis located the $m n r A$ locus to the right of $g l c A 95$, a temperature-sensitive mutation which was relieved by glucosamine (Valentine, 1975) (crosses 1, 2 and 3, Table 5). The man $A$ locus was closely linked to ribo $B$ (recombination frequency $0 \cdot 85 \pm 0 \cdot 85 \%$ ) but the order has not been determined as the nearby locus fac $A$ was not classified due to the presence of facB in the cross (cross 4, Table 5).

\section{Analysis of walls from strains grown at $40{ }^{\circ} \mathrm{C}$}

Strains BwB152 ( $\left.m n r A^{+}\right)$and Bv455 ( $\left.m n r A 455\right)$ were grown at $40{ }^{\circ} \mathrm{C}$, a semi-restrictive temperature which allowed some growth and wall synthesis by the mutant. Ballooning of the mutant strain occurred and these balloons were discernible in the purified wall preparations. An analysis was made of the sugar, lipid and protein contents of the walls from the two strains (Table 6). The most striking change was the reduction of mannose in the mutant walls to $37.5 \%$ of the control value; in addition, glucosamine was increased and galactosamine was decreased. 

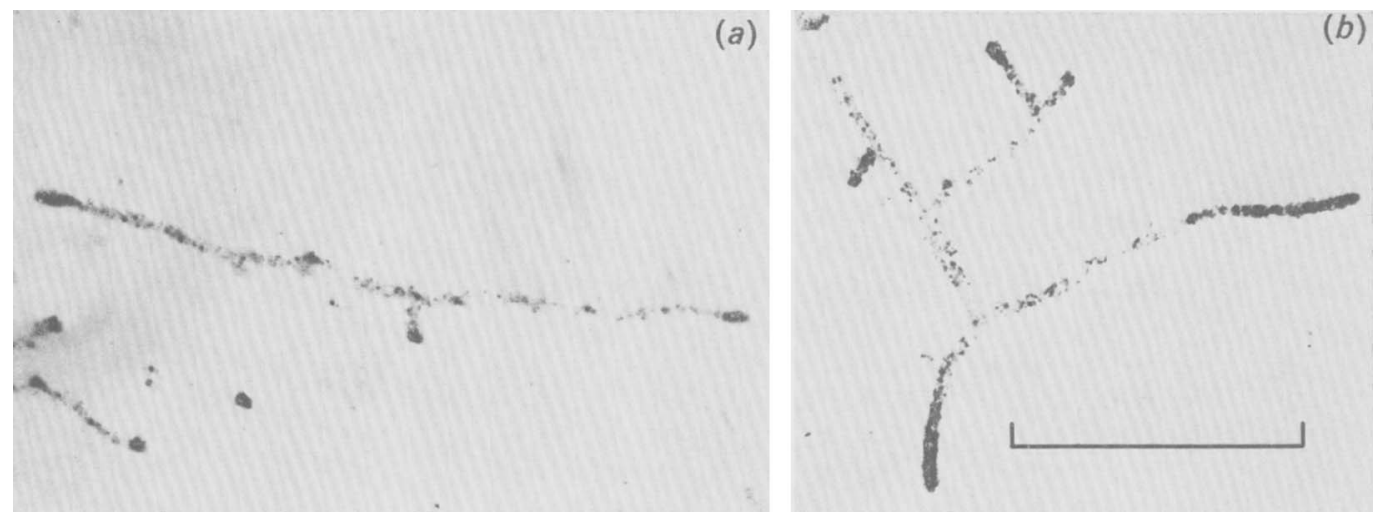

Fig. 3. Autoradiographs of hyphae of strain Bv601 ( $m$ nrA455 manAl) of $A$. nidulans labelled with $\left[2-{ }^{3} \mathrm{H}\right]$ mannose for $20 \mathrm{~min}(a)$ or $80 \mathrm{~min}(b)$. Bar marker represents $100 \mu \mathrm{m}$.

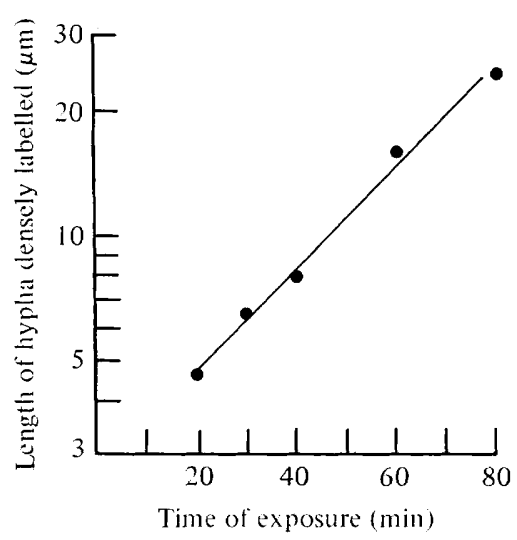

Fig. 4. Relationship between the mean length of densely labelled primary hyphal tip of $A$. nidulans strain Bv601 (mnrA455 manAl) and the time of exposure to $\left[2-{ }^{3} \mathrm{H}\right]$ mannose. Data were collected from photographs like those in Fig. 3.

\section{Incorporation studies with radioactive mannose}

As argued above, the double mutant (mnrA455 manAl) at $43{ }^{\circ} \mathrm{C}$ should have a requirement for mannose for normal wall synthesis and should be unable to utilize mannose as a carbon source. Consequently radioactive mannose supplied to the fungus should be incorporated specifically into walls and should not be converted into other products.

Autoradiography. Hyphae were labelled as described and autoradiographs were prepared (Fig. 3). Labelling was predominantly at the tip of the hyphae and, for the primary hypha, the mean length of tip that was densely labelled increased exponentially with the time of exposure to labelled mannose (Fig. 4), as would be expected for hyphae which are likely to be growing exponentially (Trinci, 1969). Densely labelled regions were taken as those in which silver grains were almost continuous.

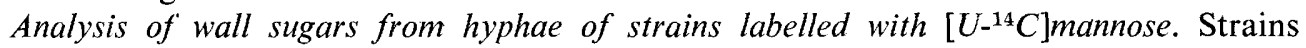
BWB152 ( $m n r A^{+} m a n A^{+}$) and Bv601 (mnrA455 manAl) were labelled with $\left[{ }^{14} \mathrm{C}\right]$ mannose, walls were purified, sugars were separated and radioactivity was counted. When grown at $30{ }^{\circ} \mathrm{C}$, вWB 152 incorporated most of the label into glucose $(50 \%)$ whereas Bv601 had the highest proportion $(44.6 \%$ ) in mannose (Table 7 ). There was twice as much labelled mannose in BV601 as in BWB152, since the manAI mutation in BV601 is expressed at $30^{\circ} \mathrm{C}$. At $43{ }^{\circ} \mathrm{C}$, BWB 152 had $32.6 \%$ radioactivity in mannose whereas Bv601 had $83.9 \%$. As Bv601 
Table 7. Percentage of total radioactivity in the major sugar components of purified walls from strains BWB152 (parental) and Bv601 (mnrA455 manAl) grown for $48 \mathrm{~h}$ on MM plus $0.95 \%$ glucose, $0.05 \%$ mannose and $\left[{ }^{14} \mathrm{C}\right]$ mannose at 30 or $43{ }^{\circ} \mathrm{C}$

\begin{tabular}{|c|c|c|c|c|c|c|}
\hline \multirow[b]{2}{*}{ Sugar } & \multicolumn{3}{|c|}{$30^{\circ} \mathrm{C}$} & \multicolumn{3}{|c|}{$43^{\circ} \mathrm{C}$} \\
\hline & BWB152 & BV601 & $\frac{\text { BV } 601}{\text { BWB } 152} \times 100$ & BWB152 & BV601 & $\frac{\text { BV } 601}{\text { BW B } 152} \times 100$ \\
\hline Glucose & $50 \cdot 0$ & $39 \cdot 2$ & $78 \cdot 4$ & $44 \cdot 7$ & $9 \cdot 4$ & $21 \cdot 0$ \\
\hline Mannose & $19 \cdot 4$ & $44 \cdot 6$ & $229 \cdot 9$ & $32 \cdot 6$ & 83.9 & $257 \cdot 4$ \\
\hline Glucosamine & $17 \cdot 5$ & $5 \cdot 9$ & $33 \cdot 7$ & $9 \cdot 7$ & $3 \cdot 1$ & $32 \cdot 0$ \\
\hline Galactose & $11 \cdot 5$ & $7 \cdot 8$ & $67 \cdot 8$ & $13 \cdot 0$ & $3 \cdot 6$ & $27 \cdot 7$ \\
\hline $10^{-5} \times$ Total d.p.m. & $4 \cdot 8$ & $7 \cdot 4$ & & $4 \cdot 92$ & $4 \cdot 77$ & \\
\hline
\end{tabular}

Table 8. Specific activities of enzymes in cell-free extracts prepared from strains BWB 152 (parental) and $\mathrm{Bv} 455$ (mnr455) grown at $30{ }^{\circ} \mathrm{C}$ on MM plus $0.5 \%$ glucose

\begin{tabular}{ccccc} 
Assay temp. & \multicolumn{2}{c}{$10^{3} \times$ Specific activity [units $\left.(\mathrm{mg} \text { protein })^{-1}\right]$} \\
Strain & $\begin{array}{c}\text { Phosphomannose } \\
\text { isomerase }\end{array}$ & $\begin{array}{c}\text { Phosphoglucose } \\
\text { mutase }\end{array}$ & $\begin{array}{c}\text { Phosphomannose } \\
\text { mutase }\end{array}$ \\
BWB152 & 30 & 40 & 60 & 3 \\
BV455 & 36 & ND & 70 & $0 \cdot 45$ \\
& 43 & 40 & ND & $0 \cdot 18$ \\
& 30 & 50 & 70 & 1 \\
& 36 & ND & ND & $* 09$ \\
& 50 & & No detectable activity.
\end{tabular}

had $16.1 \%$ radioactivity in sugars other than mannose it is evident that the mutant enzyme(s) for mannose catabolism retain some activity even at the restrictive temperature. This point will be referred to later.

\section{Enzyme assays}

Enzyme activities in strain Bv455. Strains BWB152 (mnr $\left.A^{+}\right)$and BV455 (mnrA455) were grown in MM plus $0.5 \%$ glucose at $30{ }^{\circ} \mathrm{C}$. Cell-free extracts were prepared and assays were made of phosphomannose isomerase, phosphoglucose mutase and phosphomannose mutase at 30,36 and $43{ }^{\circ} \mathrm{C}$. Activities of phosphomannose isomerase and phosphoglucose mutase showed little difference between the strains but, relative to the $m n r A^{+}$strain, the phosphomannose mutase activity in the mutant (BV455) was reduced threefold and fivefold, respectively, when assayed at 30 and $36^{\circ} \mathrm{C}$ (Table 8). Cell-free extracts from both strains were incubated at $32{ }^{\circ} \mathrm{C}$ and then assayed at $26^{\circ} \mathrm{C}$ for phosphomannose mutase. Enzyme activities from both strains were thermolabile at this temperature but the enzyme from BV455 had a shorter half-life $(2.2 \mathrm{~min})$ than that from BWB152 $(3.6 \mathrm{~min})$ (Fig. $5 \mathrm{a})$. The mutant strain therefore had lower activities of a more labile phosphomannose mutase. A further conclusion from this is that phosphoglucose mutase and phosphomannose mutase are independent activities.

Enzyme activities in strain Bv603. Strains BWB152 (manA $A^{+}$) and Bv603 (manAl) were grown in MM plus $0.475 \%$ glucose and $0.025 \%$ mannose at 30 and $43{ }^{\circ} \mathrm{C}$. Cell-free extracts were assayed for phosphoglucose isomerase and phosphomannose isomerase at $30{ }^{\circ} \mathrm{C}$. Phosphoglucose isomerase activities were similar in both strains irrespective of the growth temperature whereas, relative to the wild-type, phosphomannose isomerase showed a fourfold reduction in the mutant grown at $30{ }^{\circ} \mathrm{C}$ and at least a 40 -fold reduction when grown at $43{ }^{\circ} \mathrm{C}$ (Table 9). The observation of a reduced but detectable phosphomannose 


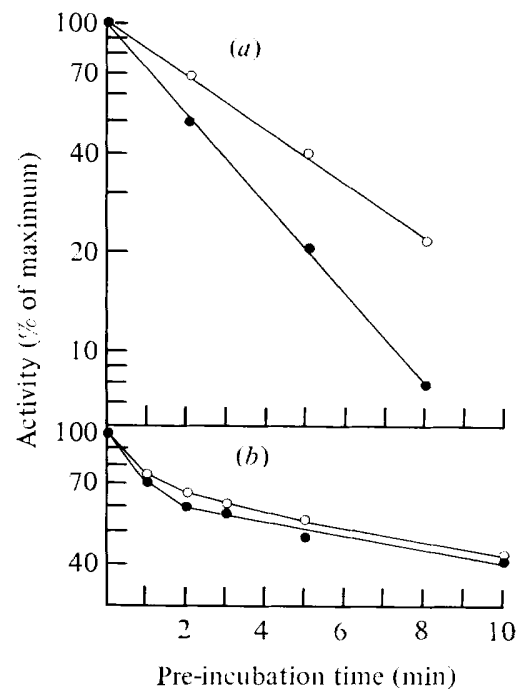

Fig. 5. (a) Influence of pre-incubation at $32{ }^{\circ} \mathrm{C}$ on the activity of phosphomannose mutase in cellfree extracts from mycelium grown at $30^{\circ} \mathrm{C}$. Enzyme assays were at $26^{\circ} \mathrm{C}$. $\bigcirc$, BWB152 (parental strain);, , Bv455 (mnr A455).

(b) Influence of pre-incubation at $46^{\circ} \mathrm{C}$ on the activity of phosphomannose isomerase in cell-free extracts from mycelium grown at $30^{\circ} \mathrm{C}$. Enzyme assays were at $30^{\circ} \mathrm{C}$. $\bigcirc$, Bws 152 (parental strain); •, Bv603 (manAl).

Table 9. Specific activities of enzymes in cell-free extracts prepared from strains $\mathrm{BW \textrm {B }} 152$ (parental) and $\mathrm{Bv} 603$ (man Al) grown at 30 or $43{ }^{\circ} \mathrm{C}$ in MM plus $0.475 \%$ glucose and $0.025 \%$ mannose and assayed at $30^{\circ} \mathrm{C}$

$\begin{array}{lccc}\text { Strain } & \begin{array}{c}\text { Growth temp. } \\ \left({ }^{\circ} \mathrm{C}\right)\end{array} & \begin{array}{c}\begin{array}{c}\text { Phosphoglucose } \\ \text { isomerase }\end{array} \\ {\left[\begin{array}{c}\text { [units }(\mathrm{mg} \text { photein) } \\ \text { P-1] }\end{array}\right.}\end{array} & \begin{array}{c}\text { Phosphomannose } \\ \text { isomerase }\end{array} \\ \text { BWB152 } & 30 & 1800 & 80 \\ \text { BV603 } & 43 & 1400 & 40 \\ & 30 & 1900 & 20 \\ & 43 & 1800 & <1\end{array}$

isomerase activity at $30^{\circ} \mathrm{C}$ confirms the mutant phenotype observed from radial growth rates (Fig. $2 b$ ). Cell-free extracts from cultures grown at $30{ }^{\circ} \mathrm{C}$ were incubated at $46{ }^{\circ} \mathrm{C}$ and then, at intervals, assayed for phosphomannose isomerase activity at $30^{\circ} \mathrm{C}$. No difference could be detected in thermolability (Fig. $5 b$ ), which explains why some ${ }^{14} \mathrm{C}$ from mannose is found in the glucose, glucosamine and galactose of the walls of the double mutant even when the strain is grown at $43{ }^{\circ} \mathrm{C}$ (Table 7). Although there is a very low level of phosphomannose isomerase in the mnrA455 manAl strain (Bv601) the enzyme is not very thermolabile and is presumably able to convert mannose 6-phosphate into fructose 6-phosphate and thence into glucose.

\section{DISCUSSION}

When strains containing the $m n r A$ mutation were grown on glucose at restrictive and semi-restrictive temperatures, they produced balloons which had less mannose in their walls than occurs in normal hyphae. Thus the decreased content of a mannose-containing wall polymer may be responsible for the loss of polarized growth of the hyphae. Similar ballooning accompanied by a reduction in glucosamine and galactosamine in the wall has 
been reported in another temperature-sensitive mutant of $A$. nidulans (Cohen et al., 1969; Katz \& Rosenberger, 1970). These walls were found to be fragile and easily lysed and the balloons could be eliminated by adding $6 \%$ sodium chloride to the growth medium. In contrast, $m n r A$ balloons were not fragile and survived the cell disruption procedures, and osmotic stabilizers like sodium chloride did not eliminate the ballooning phenotype (Valentine, 1975). The walls, rather than lacking a polymer essential for rigidity, have developed in an abnormal unpolarized way. Further evidence for this is the increased affinity of the walls for the fluorescent dye Photine, an effect normally only seen at the tip of hyphae or at septa (Gull \& Trinci, 1974). The dye had better access to $\beta$-linked carbohydrates presumably due to an alteration in wall structure. Hunsley \& Kay (1976) have argued, from studies of enzyme digestion of Neurospora crassa walls, that the maintenace of shape does not reside in any one polymer. It is important, however, to distinguish between the maintenance of hyphal structure and the production of a particular shape by the growing hypha. It is possible that, in the initial stages of wall synthesis, quite minor polymers may be essential for the formation of the hyphal tube. Other more abundant polymers such as chitin and glucans would then rigidify within the initial network. Thus a mannose-containing polymer may be necessary for normal wall synthesis. There is evidence that ballooning can also be caused by other genetic lesions; C. F. Roberts (personal communication) has observed ballooning of other sugar mutants and Valentine (1975) has reported a further 14 loci where temperature-sensitive lesions produce ballooning.

The reported composition of the $A$. nidulans wall varies according to the growth conditions and methods of wall purification and analysis (Bull, 1970; Katz \& Rosenberger, 1970; Zonneveld, 1971). Variation is likely to occur in protein and lipid content, depending on the purity of the wall preparation. Protein contents of between 5 and $12 \%$ have been reported by the above authors and the figure of $3.5 \%$ reported here suggests that the walls have little contaminating cytoplasm. The galactose content was higher than previous estimates. Galactose has been found to be associated with a lipid fraction; $54 \%$ of the total galactose can be isolated in glycolipid which has been analysed by thin-layer chromatography (Valentine, 1975).

The inhibition of the growth of mnrA strains on $0.9 \%$ glucose $10.1 \%$ mannose can be explained in three ways. First, there could be competition for a common permease system which resulted in the reduced uptake of mannose. Secondly, there could be competition for phosphorylating enzymes within the cell resulting in reduced concentrations of phosphorylated mannose which would effectively give mannose starvation. Thirdly, there could be inhibition due to the accumulation of phosphorylated sugars caused by a biochemical block in the conversion of glucose into mannose for wall synthesis. Competition for permeases and phosphorylating enzymes has been suggested for similar inhibition of mannose-negative mutants of Saccharomyces cerevisiae by glucose and mannose (Herrera et al., 1976). The $50 \%$ inhibition of the growth of the $m n r A$ strain on $0.9 \%$ mannose $10.1 \%$ glucose is consistent with a reported 10 -fold higher affinity of glucose over mannose for the sugar transport of $S$. cerevisiae (Cirillo, 1968). Inhibition of fungal mutants by mixtures of sugars has been reported for glucose/glucosamine in $A$. nidulans (Katz \& Rosenberger, 1970), glucose /fructose in N. crassa (Murayama \& Ishikawa, 1975) and glucose/mannose in $S$. cerevisiae (Herrera et al., 1976).

A pathway which shows how mannose could be used as a wall precursor and as a carbon and energy source can be proposed on the basis of the results (Fig. 6). The lesion in the $m n r A$ strain is in phosphomannose mutase and this is likely to be the structural gene for this enzyme as the mutant enzyme is more thermolabile than the wild-type. A defect in this enzyme explains the specific requirement of the strain for mannose as glucose cannot be converted to mannose 1-phosphate. The addition of mannose can by-pass this block presumably by phosphorylation at the 6-position for conversion to glucose and also directly at the 1-position for utilization as a wall precursor. The addition of glucose to a $m n r A$ 


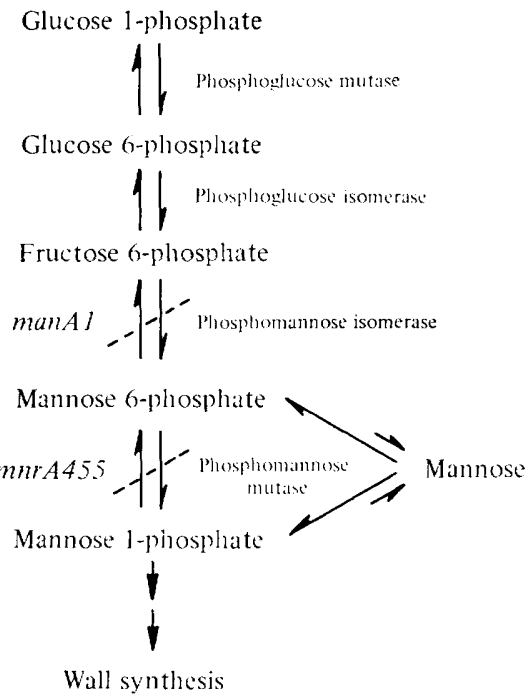

Fig. 6. Proposed pathway for the utilization and interconversion of mannose and mannose monophosphates in A. nidulans.

culture growing on mannose would cause inhibition by any of the mechanisms previously discussed but might result from the accumulation of mannose 6-phosphate. Glucose 6phosphate accumulation has been shown to correlate with suppression of RNA synthesis in S. cerevisiae (Maitra, 1971). The second mutation, manA, appears to affect the regulation of phosphomannose isomerase synthesis. The reduction in the activity of this enzyme might reduce the accumulation of mannose 6-phosphate or might release mannose for wall synthesis as discussed previously. The double mutant would therefore be able to grow on mixtures of mannose and glucose but not on glucose alone, as mannose could not be synthesized from it. This failure to grow on glucose alone is an interesting property considering that selection was made on a mixture of glucose and mannose. It is evidently a consequence of the pathway for mannose synthesis. The failure to grow on mannose alone is more expected, presumably due to inability to use the sugar as a carbon and energy source. Conclusions on the mechanisms involved must await experiments on the uptake of glucose and mannose and on the concentrations of phosphorylated sugars in the fungus grown under different conditions. The mutant strains were not affected in their activities of phosphoglucose isomerase or phosphoglucose mutase which indicates that these activities are distinct from the equivalent phosphomannose isomerase and phosphomannose mutase activities.

The double mutant incorporated $84 \%$ of radioactive mannose into wall mannose and this was found predominantly at the tip of the growing hyphae. This confirms the importance of mannose in tip growth and indicates that it is incorporated at an early stage of hyphal tip growth which agrees with previous results for glucosamine in $A$. nidulans (Katz \& Rosenberger, 1970) and other fungi (Gooday, 1971). Phosphoglucose mutase mutants have been isolated in $N$. crassa (Brody \& Tatum, 1967) and in A. nidulans (Elorza \& Arst, 1971). Both strains were morphologically abnormal with excessive hyphal branching and compact colony growth. They have been reported to have' decreased glucose or $(1 \rightarrow 3)-\beta$ linked glucans in the walls. The phosphomannose mutase defect reported here has a more drastic effect on morphology and it is possible that normal amounts of mannose are more important than the normal level of glucose in the wall.

Mutants with defective phosphomannose isomerase have been isolated in S. cerevisiae as strains unable to grow on mannose but able to grow on glucose (Herrera et al., 1976). 
Addition of mannose to cells growing on glycerol, glucose or fructose inhibited growth in a similar fashion to the results presented here. However the systems are not identical as the A. nidulans man $A$ strain failed to grow on glucose alone, conditions under which the yeast strains could grow, suggesting either that mannose is not essential for wall synthesis in yeast or that isoenzymes are present which can convert glucose into mannose for wall synthesis. Yeast cells are known to have a surface mannan and mutants with defective mannans have been detected by their failure to agglutinate antisera (Raschke et al., 1973). No mutant was isolated which completely lacked mannan and the authors have suggested that such a mutant may be lethal. Phosphoglucose isomerase mutants but not phosphomannose isomerase mutants have been isolated in N. crassa (Maitra, 1971; Murayama \& Ishikawa, 1975). These strains failed to grow or grew poorly on glucose or sucrose but grew well on fructose. However growth on glucose was stimulated by the addition of fructose in a ratio of $1: 2$ fructose to glucose (Murayama \& Ishikawa, 1975) and was inhibited by a ratio of 5:1 (Maitra, 1971). These results parallel the behaviour of $\operatorname{man} A$ strains on mixtures of mannose and glucose.

This is the first report of a phosphomannose mutase deficient mutant in fungi and the use of the $m n r A$ and man $A$ mutants is likely to increase our understanding of the mechanism of wall synthesis in fungi and the distribution of mannose-containing polymers in the wall.

We thank the Science Research Council for the award of a research studentship to B.P.V. We are grateful for helpful discussions with Drs C. F. Roberts and C. T. Thurston.

\section{REFERENCES}

Bainbridge, B. W. (1974). A simple and rapid technique for obtaining a high proportion of hybrid cleistothecia in Aspergillus nidulans. Genetical Research, Cambridge 23, 115-117.

BoeHringer MANnHEIM (1975). Biochemical Information II. Mannheim, F.R.G.: Boehringer Mannheim.

Brody, S. \& Tatum, E. L. (1967). Phosphoglucomutase mutants and morphological changes in Neurospora crassa. Proceedings of the National Academy of Sciences of the United States of America 58, 923-930.

Bull, A. T. (1970). Chemical composition of wildtype and mutant Aspergillus nidulans cell walls. The nature of polysaccharides and melanin constituents. Journal of General Microbiology 63, 75-94.

CiRillo, V. F. (1968). Relationship between sugar structure and competition for the sugar transport system in bakers' yeast. Journal of Bacteriology 95, 603-611.

Clutterbuck, A. J. (1974). Aspergillus nidulans. In Handbook of Genetics, vol. I, pp. 447-510. Edited by R. C. King. New York: Plenum Publishing Corporation.

Clutterbuck, A. J. \& Sinha, U. K. (1966). Nmethyl- $N^{\prime}$-nitro- $N$-nitrosoguanidine (NTG) as a mutagen for Aspergillus nidulans. Aspergillus Newsletter 7, 12-13.

Cohen, J., Katz, D. \& Rosenberger, R. F. (1969). Temperature-sensitive mutant lacking aminosugar in its cell wall. Nature, London 224, 713-715.

FlorZA, M. V. \& ARST, H. N. (1971). Sorbose resistant mutants of Aspergillus nidulans. Molecular and General Genetics 111, 185-193.

Gooday, G. W. (1971). An autoradiographic study of hyphal growth of some fungi. Journal of General Microbiology 67, 125-133.

Gull, K. \& Trinci, A.. P. J. (1974). Detection of areas of wall differentiation in fungi using fluorescent staining. Archives of Microbiology 96, 53-57.

Herrera, L. S., Pascual, C. \& Alvarez, X. (1976). Genetic and biochemical studies of phosphomannose isomerase deficient mutants of Saccharomyces cerevisiae. Molecular and General Genetics 144, 223-230.

Horecker, B. L. \& Kornberg, A. (1948). The extinction coefficients of the reduced band of pyridine nucleotides. Journal of Biological Chemistry 175, 385-390.

HunSLEY, D. \& KAY, D. (1976). Wall structure of the Neurospora hyphal apex: immunofluorescent localization of wall surface antigens. Journal of General Microbiology 95, 233-248.

JoHnston, I. R. (1965). The composition of the cell wall of Aspergillus niger. Biochemical Journal 96, 651-658.

KATZ, D. \& Rosenberger, R. F. (1970). A mutation in Aspergillus nidulans producing hyphal walls which lack chitin. Biochimica et biophysica acta 208, 452-460.

KATZ, D. \& Rosenberger, R. F. (1971). Hyphal wall synthesis in Aspergillus nidulans: effect of protein synthesis inhibition and osmotic shock on chitin insertion and morphogenesis. Journal of Bacteriology 108, 184-190.

LHOAS, P. (1961). Mitotic haploidisation by treatment of Aspergillus niger diploids with $p$-fluorophenylalanine. Nature, London 190, 744.

Lowry, O. H., Rosebrough, N. J., FARr, A. L. \& Randall, R. J. (1951). Protein measurement with 
the Folin phenol reagent. Journal of Biological Chemistry 193, 265-275.

Macintosh, M. E. \& Pritchard, R. H. (1963). Production and replica plating of micro-colonies of Aspergillus nidulans. Genetical Research, Cambridge 4, 320-322.

Maeda, H. \& Ishida, N. (1967). Specificity of binding of hexapyranosyl polysaccharides with fluorescent brighteners. Journal of Biochemistry 62, 276-278

Mahadevan, P. R. \& Tatum, E. L. (1965). Relationship of the major constituents of the Neurospora crassa cell wall to wild-type and colonial morphology. Journal of Bacteriology 90, 10731081.

Maitra, P. K. (1971). Glucose and fructose metabolism in a phosphoglucoisomeraseless mutant of Saccharomyces cerevisiae. Journal of Bacteriology 107, 759-769.

Murayama, T. \& Ishikawa, T. (1975). Characterization of Neurospora crassa mutants deficient in glucosephosphate isomerase. Journal of Bacteriology 122, 54-58.

Newton, B. A. (1954). Site of action of polymixin on Pseudomonas aeruginosa: antagonism by cations. Journal of General Microbiology 10, 491-499.

Pontecorvo, G., Roper, J. A., Hemmons, L. M., MacDonald, K. D. \& Bufton, A. W. J. (1953).
The genetics of Aspergillus nidulans. Advances in Genetics 5, 141-238.

Raschke, W. C., Kern, K. A., Anatalis, C. \& Ballou, C. E. (1973). Genetic control of yeast mannan structure, isolation and characterization of mutants. Journal of Biological Chemistry 248, 4660-4666.

Stoffyn, P. J. \& Jeanloz, R. W. (1954). Identification of amino-sugars by paper chromatography. Archives of Biochemistry and Biophysics 152, 373379.

Taylor, I. E. P. \& Cameron, D. S. (1973). Preparation and quantitative analysis of fungal cell walls : strategy and tactics. Annual Review of Microbiology 127, 243-259.

TrincI, A. P. J. (1969). A kinetic study of the growth of Aspergillus nidulans and other fungi. Journal of General Microbiology 57, 11-24.

VAlentine, B. P. (1975). The isolation and characterization of temperature sensitive mutants of Aspergillus nidulans with special reference to cell wall synthesis and mannose utilization. Ph.D. thesis, University of London.

WlLson, C. M. (1959). Quantitative determination of sugars on paper chromatograms. Analytical Chemistry 31, 1199-1201.

ZONNEVELD, B. J. M. (1971). Biochemical analysis of the cell wall of Aspergillus nidulans. Biochimica et biophysica acta 249, 506-514. 